\title{
Less increase of copeptin and MR-proADM due to intervention with selenium and coenzyme Q10 combined: Results from a 4-year prospective randomized double-blind placebo- controlled trial among elderly Swedish citizens.
}

Urban Alehagen, Jan Aaseth and Peter Johansson

\section{Linköping University Post Print}

\section{Tweet}

N.B.: When citing this work, cite the original article.

Original Publication:

Urban Alehagen, Jan Aaseth and Peter Johansson, Less increase of copeptin and MR-proADM due to intervention with selenium and coenzyme Q10 combined: Results from a 4-year prospective randomized double-blind placebo-controlled trial among elderly Swedish citizens., 2015, Biofactors, (41), 6, 443-452.

http://dx.doi.org/10.1002/biof.1245

Copyright: IOS Press / Wiley

http://eu.wiley.com/WileyCDA/

Postprint available at: Linköping University Electronic Press

http://urn.kb.se/resolve?urn=urn:nbn:se:liu:diva-124294 
2 Less increase of Copeptin and MR-proADM due to intervention with

3 selenium and coenzyme Q10 combined. Results from a four-year

4 prospective randomized double-blind placebo-controlled trial among

5 elderly Swedish citizens.

7

8 Urban Alehagen ${ }^{1^{*}}$, Jan Aaseth ${ }^{2}$

9 and Peter Johansson ${ }^{3}$

1 :Department of Cardiology and, Department of Medical and Health Sciences,

2 : Research Department, Innlandet Hospital Trust and Hedmark University College, Norway. E-mail address: jaol-aas@online.no

3 : Department of Cardiology and, Department of Medical and Health Sciences,

peter.johansson@aries.vokby.se 
* Corresponding author:

Urban Alehagen, PhD, MD

e-mail: urban.alehagen@liu.se

Address: Dept. of Cardiology

$\underline{\text { University Hospital }}$

SE-581 85 Linköping

$\underline{\text { Sweden }}$

Phone: +46-10-1030000

Fax: +46-10-1032294

Word count: 3796 Number of Tables: 2, Number of figures: 5

Keywords: copeptin, MR-proADM, intervention, selenium, coenzyme Q10

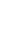
ABSTRACT

Intervention with selenium and coenzyme Q10 have recently been found to reduce mortality and increase cardiac function. The mechanisms behind these effects are unclear. As selenium and coenzyme Q10 is involved in the anti-oxidative defence, the present study aimed to evaluate effects of selenium and coenzyme Q10 on copeptin and adrenomedullin as oxidative stress biomarkers.

Therefore 437 elderly individuals were included and given intervention for 4 years.

Clinical examination and blood samples were undertaken at start and after 18 and 48 months. Evaluations of copeptin and MR-proADM changes were performed using 
repeated measures of variance. Cardiovascular mortality was evaluated using a 10year-period of follow-up, and presented in Kaplan-Meier plots.

A significant increase in copeptin level could be seen in the placebo group during the intervention period (from $9.4 \mathrm{pmol} / \mathrm{L}$ to $15.3 \mathrm{pmol} / \mathrm{L}$ ), compared to the active treatment group. The difference between the groups was confirmed in the repeated measurement of variance analyses $(P=0.031)$ with less copeptin increase in the active treatment group. Furthermore, active treatment appeared to protect against cardiovascular death both in those with high and with low copeptin levels at inclusion. Less increase of MR-proADM could also be seen during the intervention in the active treatment group compared to controls $(P=0.026)$. Both in those having an MRproADM level above or below median level, significantly less cardiovascular mortality could be seen in the active treatment group ( $P=0.0001$, and $P=0.04$ respectively). In conclusion supplementation with selenium and coenzyme Q10 during four years resulted in less concentration of both copeptin and MR-proADM. A cardioprotective effect of the supplementation was registered, irrespective of the initial levels of these biomarkers, and this protection was recognized also after 10 years of observation.

The main study was registered at Clinicaltrials.gov, and has the identifier NCT01443780. 
We have previously reported on the effect of dietary supplementation of selenium and coenzyme Q10 on an elderly community population in Sweden [1].The supplementation resulted in improved cardiac function as assessed by echocardiography and decreased cardiovascular mortality, as compared to the controls. To the authors' knowledge, no other reports using this combined intervention are found in the literature, with the exception of a small study on patients with acute myocardial infarction [2]. There are reports on positive effects of intervention with coenzyme Q10, as can be seen in the QSYMBIO study [3]. With regard to selenium, Rees et al. published a Cochrane report indicating no effect of the supplementation on mortality [4]. But, as the authors state, $95 \%$ of their included patients originated from the SELECT or the NPC trials, thus essentially involving US populations. which have relatively high basic selenium intake, with estimated mean selenium intake of $134 \mu \mathrm{g} /$ day in males and $93 \mu \mathrm{g} /$ day in females [5]. This is substantially higher than European levels [6]. Thus, the need for supplementation in US populations could be questioned, and this could also provide an explanation for inconsistent results of selenium supplementation.

Selenium, one of the trace elements, is essential for all living cells [7, 8]. It is mostly found as selenoproteins in the body, including glutathione peroxidases, thioredoxin reductase and selenoprotein $P$, which protects against oxidative stress [9].

However, selenium is also important in the inflammatory response in different disease states [10], and increased vascular oxidative stress and endothelial dysfunction have been reported to characterize patients with coronary heart disease $[11,12]$. An important interrelationship between selenium and coenzyme Q10 (ubiquinone) is the catalytic role of selenoproteins in the metabolic conversion of ubiquinone to ubiquinol, the active form of coenzyme Q10 [11]. Furthermore, the 
presence of coenzyme Q10 is needed for the optimal synthesis of selenocysteinecontaining enzymes $[13,14]$. Reduced coenzyme Q10 (ubiquinol) is an important antioxidant, effectively protecting against lipid peroxidation $[15,16]$, and it also reduces inflammatory response [17], also in those with diabetes [18]. However, the endogenous synthesis of coenzyme Q10 decreases after the age of 20, and the myocardial production is reduced to half at the age of 80 years [19]. Thus, elderly people living in geographical areas with low selenium content in the soil and food may have reduced protection against oxidative stress. Thus, restoration of the antioxidative capacity by supplementation with selenium and coenzyme Q10 could be one of the underlying mechanisms behind our previously reported positive results [1]

The biomarker vasopressin (AVP) is released from the neurohypophysis in response to different types of stressors, including oxidative stress but also in response to changes in plasma osmolality. AVP is involved in osmoregulation and cardiovascular homeostasis. The plasma concentration of AVP increases in patients with heart failure, and especially in response to left ventricular dysfunction [20]. However, as AVP is degraded rapidly in the circulation, it is not a useful plasma biomarker in clinical settings. Instead, copeptin, the C-terminal fragment of pro-vasopressin, has emerged as a promising surrogate marker for the AVP response, and copeptin measurements have also been shown to be useful in the handling of patients with cardiovascular disease [21-24]. A special emphasize on the association between copeptin and cardiovascular mortality in different conditions should be mentioned [2528] 
Adrenomedullin (ADM), another promising biomarker, possesses vasoactive properties [29] and appears to reflect and counteract oxidative stress, as shown in a mice model by Shimosawa et al. [30]. Thus high levels of adrenomedullin may indicate substantial oxidative stress. PreproADM is the precursor of ADM, and in addition to ADM itself, the mid-regional part of this precursor (MR-proADM) is released to the circulation [31]. As measuring ADM in plasma has proven to be difficult owing to its rapid attachment to the binding protein, complement factor $\mathrm{H}$, and its short half-life in the circulation, MR-proADM measurement acts as a reliable ADM surrogate marker in the circulation, and is easier to monitor.

Supplementation with selenium and coenzyme Q10 has the potential to protect against oxidative stress. Theoretically, this should decrease or stabilize the levels of copeptin and MR-proADM.

The present study report that the concentrations of copeptin and MR-proADM decreases or stabilizes as a result of the intervention. Secondly, the project could present a reduced cardiovascular mortality in the active intervention group, irrespective of the levels of the two biomarkers also after a 10 years of follow-up.

\section{Study population}

\section{METHODS}

This is a secondary analysis of a prospective randomized double-blind placebocontrolled trial in an elderly community population of 443 individuals with an age 
range of 70-88 years. The trial has been previously reported [1, 32]. All participants received the intervention for 48 months, during which they were re-examined every six months. In the study, 221 individuals received active supplementation of 200 $\mu \mathrm{g} /$ day organic selenium (SelenoPrecise $®$, Pharma Nord, Denmark), plus 200 mg/day of coenzyme $\mathrm{Q}_{10}$ (Bio-Quinon®, Pharma Nord, Denmark), and 222 individuals received a placebo. At inclusion, all participants went through a clinical examination, new patient records were obtained, the New York Heart Association functional class was assessed, and an ECG and Doppler-echocardiography were performed. Informed consent was obtained from each patient. All participants gave their informed consent. The study was approved by the Regional Ethical Committee ( diary number 03-176) and conforms to the ethical guidelines of the 1975 Declaration of Helsinki. (The Medical Product Agency declined to review the study protocol since the study was not considered a trial of a medication for a certain disease but rather one of food supplement commodities that are commercially available).

All mortality was registered, and followed until 10 years after the end of the study.

\section{Blood samples}

Blood samples were collected while the participants were resting in a supine position. Pre-chilled, EDTA vials were used. The vials were centrifuged at $3000 \mathrm{~g},+4^{\circ} \mathrm{C}$, and were then frozen at $-70^{\circ} \mathrm{C}$. No sample was thawed more than once.

\section{NT-proBNP and copeptin analyses}


ProBNP 1-76 (NT-proBNP) was measured on the Elecsys 2010 platform (Roche Diagnostics, Mannheim, Germany). Total CV was $4.8 \%$ at $26 \mathrm{pmol} / \mathrm{L}$ and $2.1 \%$ at 503 pmol/L. Plasma copeptin was measured on the Kryptor Compact platform (BRAHMS Gmbh, Hennigsdorf, Germany). The interassay CVs were $<15 \%$ at $20 \mathrm{pmol} / \mathrm{L},<13 \%$ for 20-50 pmol/L, and $<8 \mathrm{pmol} / \mathrm{L}$ for concentrations $>50 \mathrm{pmol} / \mathrm{L}$ according to previous validation [33] and information from the manufacturer[33].

\section{MR-proADM}

MR-proADM was analyzed with the use of a commercially available assay on the Kryptor platform (BRAHMS Gmbh, Hennigsdorf, Germany) [31]. The interassay coefficient of variation was $<20 \%$ for samples from 0.2 to $0.5 \mathrm{nmol} / \mathrm{L},<11 \%$ for samples from 0.5 to $2 \mathrm{nmol} / \mathrm{L}$, and $<10 \%$ for samples from 2 to $6 \mathrm{nmol} / \mathrm{L}$.

\section{Statistics}

Descriptive data are presented as percentages or mean \pm SD. The Student's unpaired two-sided $T$-test was used for continuous variables. Evaluation of the effects of treatment was based on the group mean, but the values of the individual participant were identified during three different measured time points (baseline, 18, and 48 months) using a repeated measures of variance analysis. Kaplan-Meier plots of cardiovascular mortality for the period of up to 10 years were made separately for copeptin and MR-proADM, each divided in two at their median levels. The term 'censored participants' refers to those still living at the end of the study, or who had died for reasons other than cardiovascular disease. 'Completed participants' refer to 
187 those who died due to cardiovascular disease. Evaluation of the $P$-values of mortality differences between the two groups was based on lifetable analyses using cumulative proportion surviving, and the standard error of cumulated survival to obtain a z-value. Cox proportional hazard regression analysis was used to evaluate the risk of cardiovascular mortality where a follow-up period of up to 10 years was applied. The independent variables included in the multivariate model were variables known to be associated with CV mortality: age, male gender, smoking, hyperlipidemia, diabetes, $\mathrm{Hb}<120 \mathrm{~g} / \mathrm{L}$, obstructive pulmonary disease, hypertension, ischemic heart disease, ejection fraction (EF)<40\%, ACE-inhibitor treatment, and treatment with diuretics.

$P$-values $<0.05$ were considered significant, based on a two-sided evaluation. All data were analysed using standard software (Statistica v. 12.0, Statsoft Inc, Tulsa, OK, USA.).

$$
\text { RESULTS }
$$

The baseline characteristics of the study population are presented in Table 1, and a CONSORT flow chart of the study is presented in Fig.1. The follow-up period in the main publication was 1900 days, as indicated in Fig.1.

It can be seen that the final population consisted of 437 individuals, as samples for evaluation of MR-proADM and copeptin were not present in six of the 443 individuals primarily included. Of the total population, 216 individuals in the active supplementation group, and 221 in the placebo group were evaluated. The mean age at the start of the intervention was approximately 77 years, and the size of the male 
and female fractions were practically equal in the groups. The active treatment group and placebo group were well balanced in all baseline variables (Table 1), except that the placebo group had a larger proportion receiving treatment with ACE-inhibitors (24\% vs. $15 \% ; P=0.02$ ). No differences could be seen regarding history of diabetes or ischemic heart disease between the two groups.

At inclusion, the concentrations of NT-proBNP were almost equal in the two groups (537 ng/L vs. $516 \mathrm{ng} / \mathrm{L})$. These mean concentrations were not as high as in patients with overt heart failure [34]. At the study start, about 7\% in both groups had impaired heart function, here defined as EF $<40 \%$, according to echocardiography. The distribution of the different quartiles of plasma concentration of the two biomarkers in the different EF classes according to echocardiography are presented in Table 2.

\section{Copeptin and intervention with selenium and coenzyme Q10 combined}

At the study start no difference in copeptin concentrations was seen between the actively treated and the placebo group $(P=0.45)$. The mean concentration of copeptin in the active treatment group at the start was $10.7 \mathrm{pmol} / \mathrm{L}$ (SD 9.4), and at the end of the study it was $10.9 \mathrm{pmol} / \mathrm{L}$ (SD 7.2). Thus, no significant difference between the start and the end based on group mean concentration could be found in the supplemented group $(P=0.87)$. In the placebo group the copeptin concentration was 9.4 pmol/L (SD 7.4) at the start, and $15.3 \mathrm{pmol} / \mathrm{L}$ (SD 15.3) at the end of the study. Thus, a significant increase in copeptin concentration occurred in the placebo group between the start and end of the study $(P=0.001)$. 
To further explore the possible treatment effect a repeated measures of variance was performed. This evaluation showed a significant treatment effect on the copeptin level $(\mathrm{F}=4.85 ; P=0.009)$, indicating that a significant difference between active intervention and placebo existed. Evaluation of the interaction revealed a significant interaction $(F=3.54 ; P=0.03)$ indicating that the obtained treatment effect was not based on differences in the copeptin levels of the two groups at the start, but to a significantly reduced level of copeptin due to the intervention (Fig. 2).

Cardiovascular mortality was monitored during 10 years of follow-up. In this evaluation the initial plasma concentrations of copeptin were divided into two groups; above versus below the median concentration. The cardiovascular mortality during the follow-up period in those with a plasma concentration of copeptin above the median is presented in Fig. 3a, and those with a plasma concentration below the median is presented in Fig. 3b. From these evaluations a significantly decreased cardiovascular mortality $\left(X^{2}: 10.20 ; P=0.0014\right)$ could be demonstrated in those on active treatment and with a copeptin level above the median level, compared to the controls, applying a 10-year follow-up period. Also, in those with a copeptin concentration below the median at the study start, a significantly decreased cardiovascular mortality could be demonstrated in those on active supplementation, compared to the controls $\left(X^{2}: 8.47 ; P=0.0036\right)$.

In an overall risk evaluation of the cardiovascular mortality of those on active supplementation versus placebo, the risk reduction attributed to the present intervention was between 39 and $41 \%$, as seen in the multivariate model including established clinical variables influencing the risk, if copeptin at the start of the intervention was below, versus above the median concentration, when applying a follow-up time of 10 years (Table 3). 
MR-proADM and intervention with selenium and coenzyme Q10 combined

The levels of MR-proADM showed a plasma concentration of $721 \mathrm{pmol} / \mathrm{L}$ (SD 143) in the actively treated group at the study start, and $754 \mathrm{pmol} / \mathrm{L}$ (SD 203) at the study end, thus no significant change occurred during the treatment course. In the placebo group the plasma concentration of MR-proADM at the study start was $760 \mathrm{pmol} / \mathrm{L}$ (SD 169), and at the end it was $865 \mathrm{pmol} / \mathrm{L}$ (SD 241); thus, there was a significant increase of the mean level of MR-proADM $(p=0.01)$.

Performing the same procedure as described above, to evaluate a possible treatment effect of selenium and coenzyme Q10 on the MR-proADM level, showed a significant treatment effect $(\mathrm{F}=10.78 ; P<0.0001)$, and a significant interaction $(\mathrm{F}=3.70 ; P=0.03)$. Thus, a significant treatment effect was seen on the MR-proADM level (Fig. 4).

On evaluation of cardiovascular mortality during 10 years of follow-up the plasma concentrations of MR-proADM were divided into two subgroups, above versus below the median level. The cardiovascular mortality during the follow-up period in those with a plasma concentration of MR-proADM above the median is presented in Figure 5a. It was found that in those with an MR-proADM concentration at the study start above median, active supplementation resulted in significantly less cardiovascular mortality than in the controls, as registered during a follow-up period of 10 years $\left(x^{2}\right.$ : 14.56; $P=0.0001)$. Significantly reduced cardiovascular mortality in the actively treated group compared to the controls was also seen in those with an MR-proADM concentration below the median at study start ( $\left.X^{2}: 4.19 ; P=0.0406\right)($ Fig. $5 b)$.

The overall risk of cardiovascular mortality when applying a 10 year follow-up period was also evaluated as an effect of active intervention compared to placebo in those 
283 having a MR-proADM concentration above versus below the median concentration

284

285

286

287

288

289

290

291

292

293

294

295

296

297

298

299

300

301

302

303

304

305

(Table 3). A risk reduction of between 54 to $40 \%$ could be seen in the two groups as applied in a multivariate model including clinical variables influencing the risk of cardiovascular mortality.

\section{DISCUSSION}

The present report demonstrates the effect of dietary supplementation with selenium and coenzyme Q10 on the plasma concentration of the two biomarkers copeptin and MR-proADM, indicating a possible protection against oxidative stress by the intervention. Both copeptin and MR-proADM has in the literature been shown to exhibit prognostic information, especially regarding patients with heart failure [25, 3539]. However, there are also reports that there is an association between plasma concentration between the biomarkers and cardiac function, even if this association does not seem to be strong [40]. We have presented the distribution of the two biomarkers in the different quartiles in the different cardiac systolic function classes in Table 2, and there is a trend towards higher concentration of the biomarkers as the cardiac function decreases. However, as the study population consisted of retired community members from a rural municipality, the part with decreased cardiac function is small, influencing the interpretation of the Table 2.

The combination of selenium and coenzyme Q10 may result in an enhanced antioxidative action [14] . As the selenium intake in Sweden is low or suboptimal [6], the supplementation is presumed to optimize the function of several selenoenzymes 
307 [41], including the enzymatic conversion of coenzyme Q10 to its active form, ubiquinol [13]. We combined the selenium supplementation with coenzyme Q10 [41] because coenzyme Q10 apparently has positive effects on cellular oxidative stress, as seen in patients with coronary artery disease [42]. As the need for coenzyme Q10 increases during conditions of increased oxidative stress, and inflammation, as well as with increased age, there may be a need for supplementation of coenzyme Q10 in elderly patient categories, such as in the present population under investigation.

In the actively supplemented group the circulating levels of these two biomarkers did not increase significantly during the treatment course of four years, in contrast to their values in the controls, which exhibited a continuous and substantial increase.

In the literature there are data indicating that a higher level of oxidative stress results in a higher level of vasopressin, and thus also of copeptin [43]. However, there is little information regarding the expected increase due to age in an elderly healthy community population in the literature. In a sub-study to the OPTIMAAL study including patients with heart failure after myocardial infarction, Voors et al. showed a relation where in the fourth quartile of copeptin concentration a higher mean age could be found compared to those in the first quartile of copeptin concentration [23].

Our population consisted of elderly persons and might also have included individuals with various early stages of different diseases. This could explain the relatively high mean level of copeptin concentration at the study start, and the increased level at the study end in those on placebo.

With regard to MR-proADM, a similar difference appeared between the supplemented and the control groups as described above for copeptin. The levels of MR-proADM increase in the circulation with age [44]. However, according to a report from Morgenthaler et al. the mean values in healthy persons were lower than our 
values, even though their sample size in the corresponding age group was small [31]. Again, this could mean that part of the present population had disease states that influenced the mean values. However, the important observation is the effect of the intervention, where a significantly smaller increase could be seen in those given supplementation compared to the controls.

Adrenomedullin has previously been shown to protect the cardiovascular system against oxidative stress $[45,46]$. It is a reasonable hypothesis that the reductions in MR-proADM as well as in copeptin levels indicate that a lower level of oxidative stress was obtained by the intervention with selenium and coenzyme Q10, although other mechanisms of action may also have been involved.

Our hypothesis is strengthened by the analysis of cardiovascular mortality, as presented earlier [1]. We observed significantly less cardiovascular mortality in those on supplementation with selenium and coenzyme Q10 compared to placebo, and the reducing effect on cardiovascular mortality appeared to persist throughout the observation period of 10 years. The mechanism behind this long-lasting protection remains a matter of speculation. The four-year-period on supplementation may have prevented the development of irreversible or structural changes in the cardial vasculature. However, this has to be further investigated.

\section{The studied population was of limited size, 437 individuals, which makes the} interpretation of the results difficult. However, as the difference between the two groups, active supplementation versus placebo, was highly significant, it is probable that the results reflect real changes. The report should be regarded as a hypothesis- 
generating study, and as such it has interesting information that could be used in further research.

The study population was not included through a sampling process, but invited because they were living in the same rural community. This could result in a bias, resulting in a lower threshold of participation among those with known or unknown diseases, and impaired well-being hoping for a diagnosis or medical treatment adjustment. This could result in even higher levels of the two biomarkers compared to other healthy populations of corresponding age. However, the total study population was randomized into two groups, and therefore a similar health situation could be expected in those given active treatment and those on placebo. In this report only two biomarkers that are involved in a multitude of processes in the body are evaluated.

The two biomarkers monitored in this study, copeptin and MR-proADM, may reflect pathology in different locations in the body [47] and they may be influenced by various pathological processes, including cardiovascular diseases [47]. Therefore, other analyses could have been performed retrospectively that may be more specific for oxidative stress. However, the results indicating an effect on different processes by the intervention are significant as reflected by the size of the difference between those on active supplementation versus placebo, which is why the choice of the two biomarkers could be argued as reasonable.

\section{CONCLUSION}

The concentration of the biomarkers copeptin and MR-proADM reflects the intensity of oxidative stress in the body, although they may be influenced by other processes. 
Recently, data on intervention with selenium and coenzyme Q10 were presented, showing they provide significant protection for cardiac function and against cardiovascular mortality in an elderly population in Sweden. In the present study, the two biomarkers copeptin and MR-proADM did not exhibit an increase in the actively treated group compared to the placebo group. Irrespective of whether the initial levels of these biomarkers as indicators of oxidative stress were high or low, supplementation with selenium and coenzyme Q10 exerted protection against cardiovascular mortality also after 10 years of observation. The data support a hypothesis of an anti-oxidative effect of selenium and coenzyme Q10. However, the size of the sample in this study was small and thus more research in the area is needed.

Figure 1. CONSORT diagram illustrating a flow chart of the study

Figure 2. Presentation of plasma concentration of copeptin at study start, after 18 months, and after 48 months in the two groups with active treatment supplementation and placebo evaluated according to the repeated measure of variance principle.

Figure 3a. Kaplan-Meier graph illustrating cardiovascular mortality in the group with a copeptin concentration above median in those with active treatment versus placebo during a follow-up period of ten years. 
403

404

405

406

407

408

409

410

411

412

413

414

415

416

417

418

419

420

421

422

423

424

425

Figure 3b. Kaplan-Meier graph illustrating cardiovascular mortality in the group with a copeptin concentration below median in those with active treatment versus placebo during a follow-up period of ten years.

Figure 4. Presentation of plasma concentration of MR-proADM at study start, after 18 months, and after 48 months in the two groups with active treatment supplementation and placebo evaluated according to the repeated measure of variance principle.

Figure 5a. Kaplan-Meier graph illustrating cardiovascular mortality in the group with an MR-proADM concentration below median in those with active treatment versus placebo during a follow-up period of ten years.

Figure 5b. Kaplan-Meier graph illustrating cardiovascular mortality in the group with an MR-proADM concentration above median in those with active treatment versus placebo during a follow-up period of ten years.

\section{Conflict of interest}

The authors declare no conflict of interest.

\section{Author contributions}

Dr Alehagen had full access to all of the data in the study and takes responsibility for the integrity of the data and the accuracy of the data analysis.

Study concept and design: Alehagen, Aaseth, Johansson.

Acquisition of data: Alehagen, Johansson.

Analysis and interpretation of data: Alehagen, Johansson. 
426 Drafting of the manuscript: Alehagen, Johansson, Aaseth.

427 Critical revision of the manuscript: Alehagen, Aaseth, Johansson.

428 Statistical analysis: Alehagen.

429 Obtained funding: Alehagen.

430 Study supervision: Alehagen, Aaseth, Johansson.

431 Part of the analysis costs was supported by grants from Pharma Nord Aps, Denmark,

432 the County Council of Östergötland, Linköping University (UA,PJ)

433 The funding organizations had no role in the design, management, analysis,

434 interpretation of the data, preparation, review or approval of the manuscript. 


\section{References}

1. Alehagen U, Johansson P, Bjornstedt M, Rosen A, Dahlstrom U: Cardiovascular mortality and supplementation: a 5-year prospective randomized double-blind placebo-controlled trial among elderly Swedish citizens. Int J Cardiol 2013, 167(5):1860-1866.

2. Kuklinski B, Weissenbacher E, Fahnrich A: Coenzyme Q10 and antioxidants in acute myocardial infarction. Mol Aspects Med 1994, 15 Suppl:s143-147.

3. Mortensen SA, Rosenfeldt F, Kumar A, Dolliner P, Filipiak KJ et al: The effect of coenzyme Q10 on morbidity and mortality in chronic heart failure: results from Q-SYMBIO: a randomized double-blind trial. JACC Heart failure 2014, 2(6):641-649.

4. Rees K, Hartley L, Day C, Flowers N, Clarke A et al: Selenium supplementation for the primary prevention of cardiovascular disease. Cochrane Database Syst Rev 2013, 1:CD009671.

5. U.S. Department of Agriculture ARS: Nutrient Intakes from Food: Mean amounts conusmed per individual, one day, 2005-2006. wwwarsusdagov /ba/bhnrc/fsrg Accessed March 2010 2008.

6. Alehagen $U$, Johansson $P$, Bjornstedt $M$, Rosen $A$, Post $C$ et al: Relatively high mortality risk in elderly Swedish subjects with low selenium status. Eur J Clin Nutr 2015, 10.1038/ejen.2015.92.

7. Fairweather-Tait SJ, Bao Y, Broadley MR, Collings R, Ford D et al: Selenium in human health and disease. Antioxid Redox Signal 2011, 14(7):1337-1383.

8. Selenius M, Rundlof AK, Olm E, Fernandes AP, Bjornstedt M: Selenium and the selenoprotein thioredoxin reductase in the prevention, treatment and diagnostics of cancer. Antioxid Redox Signal 2010, 12(7):867-880.

9. Reeves MA, Hoffmann PR: The human selenoproteome: recent insights into functions and regulation. Cell Mol Life Sci 2009, 66(15):2457-2478.

10. Mertens K, Lowes DA, Webster NR, Talib J, Hall L et al: Low zinc and selenium concentrations in sepsis are associated with oxidative damage and inflammation. Br J Anaesth 2015, 114(6):990-999.

11. Heitzer T, Schlinzig T, Krohn K, Meinertz T, Munzel T: Endothelial dysfunction, oxidative stress, and risk of cardiovascular events in patients with coronary artery disease. Circulation 2001, 104(22):2673-2678.

12. Vassalle C, Bianchi S, Bianchi F, Landi P, Battaglia D et al: Oxidative stress as a predictor of cardiovascular events in coronary artery disease patients. Clin Chem Lab Med 2012, 50(8):1463-1468.

13. Xia L, Nordman T, Olsson JM, Damdimopoulos A, Bjorkhem-Bergman L et al: The mammalian cytosolic selenoenzyme thioredoxin reductase reduces ubiquinone. A novel mechanism for defense against oxidative stress. J Biol Chem 2003, 278(4):2141-2146.

14. Alehagen U, Aaseth J: Selenium and coenzyme Q10 interrelationship in cardiovascular diseases - A clinician's point of view. J Trace Elem Med Biol 2015, 31:157-162.

15. Bullon P, Roman-Malo L, Marin-Aguilar F, Alvarez-Suarez JM, Giampieri F et al: Lipophilic antioxidants prevent lipopolysaccharide-induced mitochondrial dysfunction through mitochondrial biogenesis improvement. Pharmacol Res 2015, 91:1-8.

16. Ito K, Watanabe C, Nakamura A, Oikawa-Tada S, Murata M: Reduced Coenzyme Q10 Decreases Urinary 8-Oxo-7,8-Dihydro-2'-Deoxyguanosine Concentrations in Healthy Young Female Subjects. J Med Food 2015, 18(8):835-840. 
17. Lee BJ, Tseng YF, Yen CH, Lin PT: Effects of coenzyme Q10 supplementation ( $300 \mathrm{mg} /$ day) on antioxidation and anti-inflammation in coronary artery disease patients during statins therapy: a randomized, placebo-controlled trial. Nutr J 2013, 12(1):142.

18. Brauner $\mathrm{H}$, Luthje $\mathrm{P}$, Grunler J, Ekberg NR, Dallner $\mathrm{G}$ et al: Markers of innate immune activity in patients with type 1 and type 2 diabetes mellitus and the effect of the anti-oxidant coenzyme Q10 on inflammatory activity. Clin Exp Immunol 2014, 177(2):478-482.

19. Kalen A, Appelkvist EL, Dallner G: Age-related changes in the lipid compositions of rat and human tissues. Lipids 1989, 24(7):579-584.

20. Chatterjee K: Neurohormonal activation in congestive heart failure and the role of vasopressin. Am J Cardiol 2005, 95(9A):8B-13B.

21. Nakamura T, Funayama H, Yoshimura A, Tsuruya $Y$, Saito M et al: Possible vascular role of increased plasma arginine vasopressin in congestive heart failure. Int J Cardiol 2006, 106(2):191-195.

22. Keller T, Tzikas S, Zeller T, Czyz E, Lillpopp L et al: Copeptin improves early diagnosis of acute myocardial infarction. J Am Coll Cardiol 2010, 55(19):2096-2106.

23. Voors AA, von Haehling S, Anker SD, Hillege HL, Struck J et al: C-terminal provasopressin (copeptin) is a strong prognostic marker in patients with heart failure after an acute myocardial infarction: results from the OPTIMAAL study. Eur Heart J 2009, 30(10):11871194.

24. Khan SQ, Dhillon OS, O'Brien RJ, Struck J, Quinn PA et al: C-terminal provasopressin (copeptin) as a novel and prognostic marker in acute myocardial infarction: Leicester Acute Myocardial Infarction Peptide (LAMP) study. Circulation 2007, 115(16):2103-2110.

25. Alehagen U, Dahlstrom U, Rehfeld JF, Goetze JP: Association of copeptin and N-terminal proBNP concentrations with risk of cardiovascular death in older patients with symptoms of heart failure. JAMA 2011, 305(20):2088-2095.

26. Maisel A, Xue Y, Shah K, Mueller C, Nowak R et al: Increased 90-day mortality in patients with acute heart failure with elevated copeptin: secondary results from the Biomarkers in Acute Heart Failure (BACH) study. Circ Heart Fail 2011, 4(5):613-620.

27. Pozsonyi Z, Forhecz Z, Gombos T, Karadi I, Janoskuti L et al: Copeptin (C-terminal pro arginine-vasopressin) is an independent long-term prognostic marker in heart failure with reduced ejection fraction. Heart Lung Circ 2015, 24(4):359-367.

28. Mellbin LG, Ryden L, Brismar K, Morgenthaler NG, Ohrvik J et al: Copeptin, IGFBP-1, and cardiovascular prognosis in patients with type 2 diabetes and acute myocardial infarction: a report from the DIGAMI 2 trial. Diabetes Care 2010, 33(7):1604-1606.

29. Kitamura K, Kangawa K, Kawamoto M, Ichiki $Y$, Nakamura S et al: Adrenomedullin: a novel hypotensive peptide isolated from human pheochromocytoma. Biochem Biophys Res Commun 1993, 192(2):553-560.

30. Shimosawa T, Shibagaki Y, Ishibashi K, Kitamura K, Kangawa K et al: Adrenomedullin, an endogenous peptide, counteracts cardiovascular damage. Circulation 2002, 105(1):106-111.

31. Morgenthaler NG, Struck J, Alonso C, Bergmann A: Measurement of midregional proadrenomedullin in plasma with an immunoluminometric assay. Clin Chem 2005, 51(10):1823-1829.

32. Johansson P, Dahlstrom O, Dahlstrom U, Alehagen U: Effect of selenium and Q10 on the cardiac biomarker NT-proBNP. Scand Cardiovasc J 2013, 47(5):281-288.

33. Morgenthaler NG, Struck J, Alonso C, Bergmann A: Assay for the measurement of copeptin, a stable peptide derived from the precursor of vasopressin. Clin Chem 2006, 52(1):112-119.

34. McMurray JJ, Adamopoulos S, Anker SD, Auricchio A, Bohm M et al: ESC guidelines for the diagnosis and treatment of acute and chronic heart failure 2012: The Task Force for the Diagnosis and Treatment of Acute and Chronic Heart Failure 2012 of the European Society of Cardiology. Developed in collaboration with the Heart Failure Association (HFA) of the ESC. Eur J Heart Fail 2012, 14(8):803-869. 
35. Stoiser B, Mortl D, Hulsmann M, Berger R, Struck J et al: Copeptin, a fragment of the vasopressin precursor, as a novel predictor of outcome in heart failure. Eur J Clin Invest 2006, 36(11):771-778.

36. Gegenhuber A, Struck J, Dieplinger B, Poelz W, Pacher R et al: Comparative evaluation of Btype natriuretic peptide, mid-regional pro-A-type natriuretic peptide, mid-regional proadrenomedullin, and Copeptin to predict 1-year mortality in patients with acute destabilized heart failure. J Card Fail 2007, 13(1):42-49.

37. Maisel A, Mueller C, Nowak R, Peacock WF, Landsberg JW et al: Mid-region pro-hormone markers for diagnosis and prognosis in acute dyspnea: results from the BACH (Biomarkers in Acute Heart Failure) trial. J Am Coll Cardiol 2010, 55(19):2062-2076.

38. von Haehling S, Filippatos GS, Papassotiriou J, Cicoira M, Jankowska EA et al: Mid-regional pro-adrenomedullin as a novel predictor of mortality in patients with chronic heart failure. Eur J Heart Fail 2010, 12(5):484-491.

39. Alehagen U, Dahlstrom U, Rehfeld JF, Goetze JP: Pro-A-type natriuretic peptide, proadrenomedullin, and $\mathrm{N}$-terminal pro-B-type natriuretic peptide used in a multimarker strategy in primary health care in risk assessment of patients with symptoms of heart failure. J Card Fail 2013, 19(1):31-39.

40. Bahrmann $\mathrm{P}$, Bahrmann A, Hofner B, Christ M, Achenbach S et al: Multiple biomarker strategy for improved diagnosis of acute heart failure in older patients presenting to the emergency department. Eur Heart J Acute Cardiovasc Care 2015, 4(2):137-147.

41. Huang $Z$, Rose $A H$, Hoffmann PR: The role of selenium in inflammation and immunity: from molecular mechanisms to therapeutic opportunities. Antioxid Redox Signal 2012, 16(7):705743.

42. Lee BJ, Huang YC, Chen SJ, Lin PT: Coenzyme Q10 supplementation reduces oxidative stress and increases antioxidant enzyme activity in patients with coronary artery disease. Nutrition 2012, 28(3):250-255.

43. Nazari A, Sadr SS, Faghihi M, Azizi Y, Hosseini MJ et al: Vasopressin attenuates ischemiareperfusion injury via reduction of oxidative stress and inhibition of mitochondrial permeability transition pore opening in rat hearts. Eur J Pharmacol 2015, 760:96-102.

44. Smith JG, Newton-Cheh C, Hedblad B, Struck J, Morgenthaler NG et al: Distribution and correlates of midregional proadrenomedullin in the general population. Clin Chem 2009, 55(8):1593-1595.

45. Rahman M, Nishiyama A, Guo P, Nagai $Y$, Zhang GX et al: Effects of adrenomedullin on cardiac oxidative stress and collagen accumulation in aldosterone-dependent malignant hypertensive rats. J Pharmacol Exp Ther 2006, 318(3):1323-1329.

46. Liu J, Shimosawa T, Matsui H, Meng F, Supowit SC et al: Adrenomedullin inhibits angiotensin II-induced oxidative stress via Csk-mediated inhibition of Src activity. Am J Physiol Heart Circ Physiol 2007, 292(4):H1714-1721.

47. Eto $\mathrm{T}$, Kato J, Kitamura K: Regulation of production and secretion of adrenomedullin in the cardiovascular system. Regul Pept 2003, 112(1-3):61-69. 
Table 1. Baseline characteristics of the study population receiving intervention of a dietary supplementation of selenium and coenzyme Q10 combined during 4 years.

\begin{tabular}{|c|c|c|c|}
\hline & Active & Placebo & $p$-value \\
\hline $\mathrm{N}$ & 216 & 221 & \\
\hline Age years mean (SD) & $76.9(3.5)$ & $77.3(3.4)$ & 0.35 \\
\hline Males/Females $n$ & $112 / 104$ & $110 / 111$ & \\
\hline \multicolumn{4}{|l|}{ History } \\
\hline Diabetes n (\%) & $46(21.3)$ & $48(21.7)$ & 0.91 \\
\hline Hypertension n (\%) & $155(71.8)$ & $168(76.0)$ & 0.31 \\
\hline Obstr. pulm disease $\mathrm{n}(\%)$ & $21(9.7)$ & $35(15.8)$ & 0.06 \\
\hline IHD n (\%) & $45(20.8)$ & $52(23.5)$ & 0.50 \\
\hline NYHA class I n (\%) & $117(54.2)$ & $107(48.4)$ & 0.23 \\
\hline NYHA class II n (\%) & $58(26.9)$ & $64(29.0)$ & 0.62 \\
\hline NYHA class III n (\%) & $40(18.5)$ & $47(21.3)$ & 0.47 \\
\hline NYHA class IV n (\%) & 0 & 0 & \\
\hline \multicolumn{4}{|l|}{ Medications } \\
\hline Aspirin n (\%) & $58(26.9)$ & $66(29.9)$ & 0.48 \\
\hline Anticoagulants n (\%) & $26(12.0)$ & $34(15.4)$ & 0.31 \\
\hline ACEI n (\%) & $32(14.8)$ & $53(24.0)$ & 0.02 \\
\hline ARB n (\%) & $10(4.6)$ & $13(5.9)$ & 0.56 \\
\hline Beta blockers n (\%) & $75(34.7)$ & $72(32.6)$ & 0.64 \\
\hline Beta2 stimulants $\mathrm{n}(\%)$ & $20(9.3)$ & $27(12.2)$ & 0.32 \\
\hline Digitalis n (\%) & $10(4.6)$ & $11(5.0)$ & 0.87 \\
\hline Diuretics n (\%) & $68(31.5)$ & $88(39.8)$ & 0.07 \\
\hline Statins n (\%) & $42(19.4)$ & $50(22.6)$ & 0.41 \\
\hline
\end{tabular}




\begin{tabular}{lccc}
\hline Examinations & & \\
$\mathrm{EF}<40 \% \mathrm{n}(\%)$ & $14(6.5)$ & $17(7.7)$ & 0.65 \\
Atrial fibrillation n (\%) & $21(9.7)$ & $20(9.0)$ & 0.81 \\
NT-proBNP ng/L mean (IQR) & $537(398)$ & $516(330)$ & 0.86 \\
Copeptin pmol/L mean (IQR) & $10.7(12.0)$ & $9.4(6.6)$ & 0.20 \\
MR-proADM pmol/L mean (IQR) & $721(161)$ & $760(254)$ & \\
\hline
\end{tabular}

Note: ACEI: ACE- inhibitors; ARB; Angiotension receptor blockers; EF: Ejection fraction; IHD; Ischemic heart disease; IQR: Inter quartile range; NT-proBNP: N-terminal fragment of proBNP; NYHA: New York Heart Association functional class; SD: Standard Deviation. 
Table 2a. Distribution of ejection fraction into the four quartiles of copeptin

\begin{tabular}{lccccc}
\hline Quartile & EF $<30 \%$ & EF $30-40 \%$ & EF 31-50\% & EF $>$ 50\% & Unclassified \\
\hline Q1, $\mathrm{n}(\%)$ & $1(0.9)$ & $1(0.9)$ & $6(5.6)$ & $100(92.6)$ & 0 \\
Q2, $\mathrm{n}(\%)$ & 0 & $4(3.7)$ & $8(7.3)$ & $97(89.0)$ & 0 \\
Q3, $\mathrm{n}(\%)$ & $3(2.8)$ & $9(8.5)$ & $17(16.0)$ & $76(71.7)$ & $1(0.9)$ \\
$\mathrm{Q} 4, \mathrm{n}(\%)$ & $3(2.7)$ & $11(9.9)$ & $20(18.0)$ & $75(67.6)$ & $2(1.8)$ \\
\hline
\end{tabular}

Note: EF: Ejection fraction as obtained from echocardiography

Table $\mathbf{2 b}$. Distribution of ejection fraction into the four quartiles of MR-proADM

\begin{tabular}{lccccc}
\hline Quartile & EF $<30 \%$ & EF $30-40 \%$ & EF 31-50\% & EF $>50 \%$ & Unclassified \\
\hline Q1, $\mathrm{n}(\%)$ & 0 & $2(1.8)$ & $9(8.3)$ & $98(89.9)$ & 0 \\
Q2, $\mathrm{n}(\%)$ & $2(1.9)$ & $4(3.7)$ & $10(9.3)$ & $92(85.2)$ & 0 \\
Q3, $\mathrm{n}(\%)$ & $2(1.8)$ & $6(5.4)$ & $12(10.8)$ & $89(80.2)$ & $2(1.8)$ \\
$\mathrm{Q} 4, \mathrm{n}(\%)$ & $2(1.9)$ & $13(12.3)$ & $20(18.9)$ & $69(65.1)$ & $2(1.9)$ \\
\hline
\end{tabular}

Note: EF: Ejection fraction as obtained from echocardiography 
Table 3. Effect of intervention of selenium and coenzyme Q10 on cardiovascular mortality in an elderly population having a copeptin or a mid-regional pro-adrenomedullin concentration above, or below median concentration, and applying a follow-up time of 10 years.

\begin{tabular}{|c|c|c|c|c|c|c|c|c|c|c|c|c|}
\hline \multirow[t]{2}{*}{ Variables } & \multicolumn{3}{|c|}{$\begin{array}{l}\text { Copeptin conc } \\
\text { below median }\end{array}$} & \multicolumn{3}{|c|}{$\begin{array}{l}\text { Copeptin conc } \\
\text { above median }\end{array}$} & \multicolumn{3}{|c|}{$\begin{array}{l}\text { MR-proADM conc } \\
\text { below median }\end{array}$} & \multicolumn{3}{|c|}{$\begin{array}{l}\text { MR-proADM conc } \\
\text { above median }\end{array}$} \\
\hline & $\begin{array}{l}\text { Hazard } \\
\text { ratio }\end{array}$ & p-value & $\begin{array}{l}95 \% \\
\text { confidence } \\
\text { interval }\end{array}$ & $\begin{array}{l}\text { Hazard } \\
\text { ratio }\end{array}$ & p-value & $\begin{array}{l}95 \% \\
\text { confidence } \\
\text { interval }\end{array}$ & $\begin{array}{l}\text { Hazard } \\
\text { ratio }\end{array}$ & p-value & $\begin{array}{l}95 \% \\
\text { confidence } \\
\text { interval }\end{array}$ & $\begin{array}{l}\text { Hazard } \\
\text { ratio }\end{array}$ & p-value & $\begin{array}{l}95 \% \\
\text { confidence } \\
\text { interval }\end{array}$ \\
\hline Age & 1.15 & 0.003 & $1.05-1.25$ & 1.17 & $<0.0001$ & $1.08-1.26$ & 1.17 & 0.004 & $1.05-1.29$ & 1.15 & 0.0001 & $1.07-1.23$ \\
\hline Male & 5.33 & $<0.0001$ & $2.74-10.38$ & 0.99 & 0.97 & $0.62-1.60$ & 2.36 & 0.02 & $1.15-4.84$ & 1.86 & 0.008 & $1.18-2.93$ \\
\hline Smoker & 1.18 & 0.79 & $0.35-3.99$ & 2.02 & 0.01 & $1.15-3.57$ & 1.09 & 0.89 & $0.34-3.47$ & 2.08 & 0.01 & $1.17-3.70$ \\
\hline Hyperlipidemia & 1.40 & 0.40 & $0.64-3.04$ & 1.08 & 0.80 & $0.60-1.92$ & 1.62 & 0.22 & $0.75-3.49$ & 0.94 & 0.84 & $0.54-1.64$ \\
\hline Diabetes & 0.99 & 0.97 & $0.46-2.11$ & 1.38 & 0.21 & $0.84-2.28$ & 1.15 & 0.75 & $0.50-2.64$ & 1.39 & 0.17 & $0.87-2.21$ \\
\hline $\mathrm{Hb}<120 \mathrm{~g} / \mathrm{L}$ & 1.33 & 0.58 & $0.49-3.63$ & 1.36 & 0.30 & $0.76-2.45$ & 0.81 & 0.78 & $0.18-3.60$ & 1.28 & 0.40 & $0.72-2.30$ \\
\hline $\begin{array}{l}\text { Obstr pulm } \\
\text { disease }\end{array}$ & 1.20 & 0.70 & $0.49-2.94$ & 1.51 & 0.20 & $0.80-2.86$ & 0.76 & 0.71 & $0.17-3.28$ & 1.58 & 0.11 & $0.90-2.75$ \\
\hline Hypertension & 0.98 & 0.96 & $0.47-2.07$ & 1.36 & 0.27 & $0.79-2.34$ & 1.39 & 0.39 & $0.66-2.95$ & 1.10 & 0.72 & $0.64-1.89$ \\
\hline IHD & 1.72 & 0.14 & $0.84-3.51$ & 1.17 & 0.58 & $0.68-2.03$ & 1.72 & 0.17 & $0.79-3.73$ & 1.15 & 0.58 & $0.70-1.89$ \\
\hline$E F<40 \%$ & 1.68 & 0.44 & $0.46-6.15$ & 0.95 & 0.90 & $0.47-1.95$ & 2.47 & 0.23 & 0.56-10.91 & 0.97 & 0.93 & $0.50-1.89$ \\
\hline ACE-inhibitors & 0.74 & 0.48 & $0.33-1.69$ & 1.21 & 0.48 & $0.72-2.04$ & 0.70 & 0.54 & $0.22-2.17$ & 1.12 & 0.65 & $0.69-1.80$ \\
\hline Diuretics & 2.07 & 0.03 & $1.09-3.92$ & 1.02 & 0.94 & $0.64-1.62$ & 1.11 & 0.78 & $0.53-2.31$ & 1.23 & 0.38 & $0.78-1.92$ \\
\hline $\begin{array}{l}\text { Selenium + } \\
\text { Q10 }\end{array}$ & 0.39 & 0.008 & $0.20-0.78$ & 0.59 & 0.02 & $0.38-0.93$ & 0.46 & 0.02 & $0.24-0.91$ & 0.60 & 0.03 & $0.38-0.95$ \\
\hline
\end{tabular}

Note: EF: Ejection fraction; IHD: Ischemic heart disease; Q10; Coenzyme Q10 
Fig 1
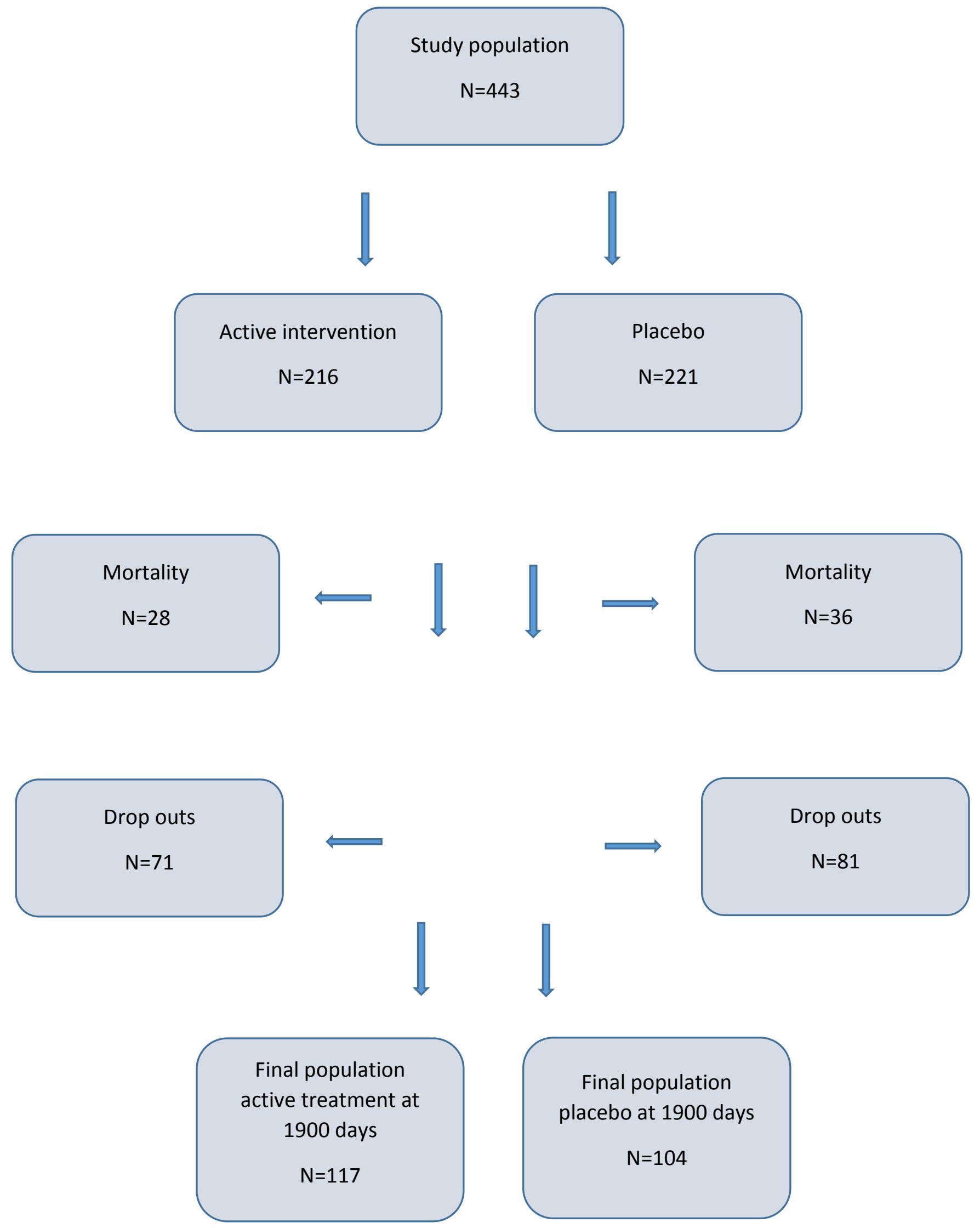
Figure 2

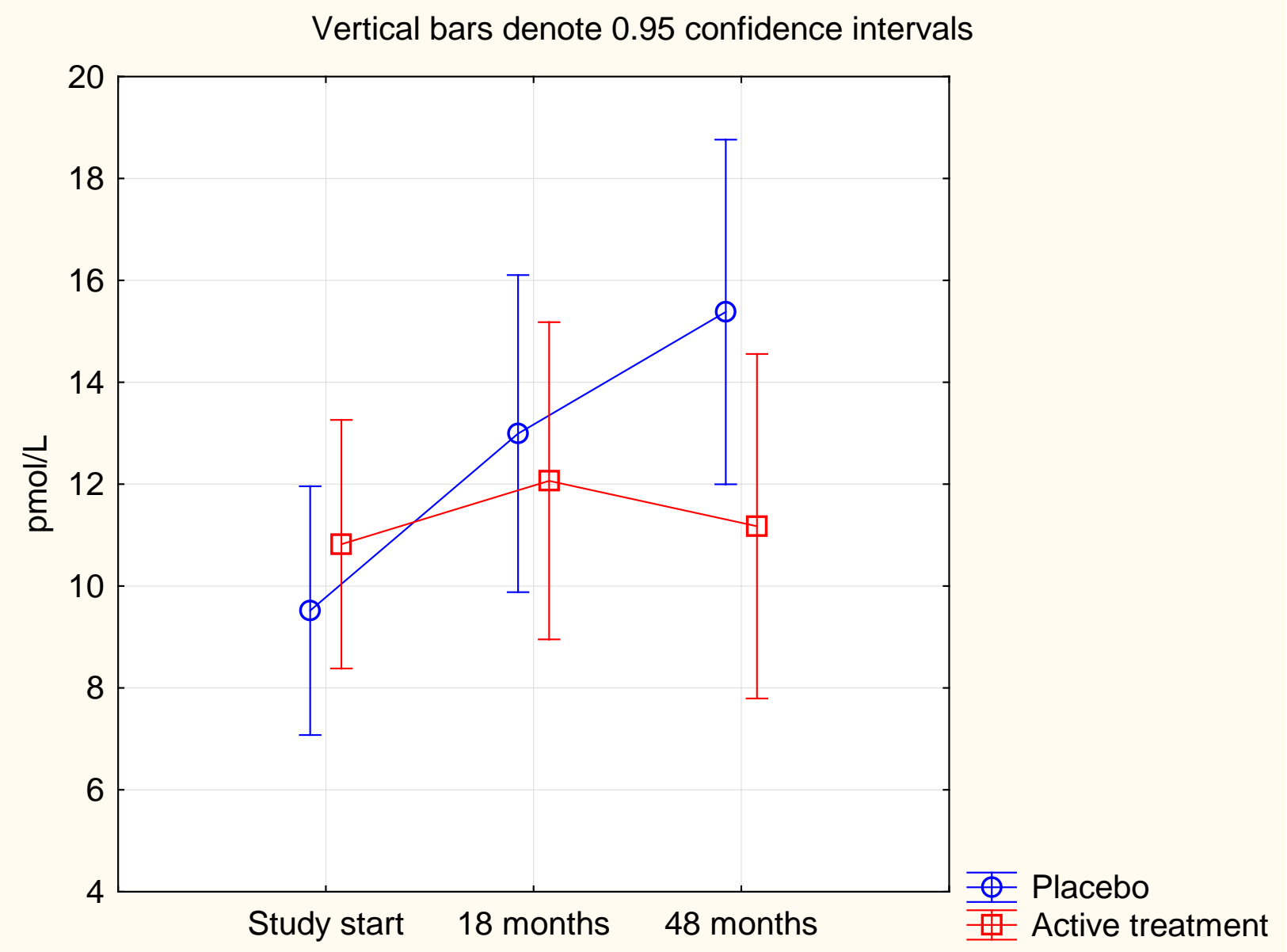


Figure $3 a$

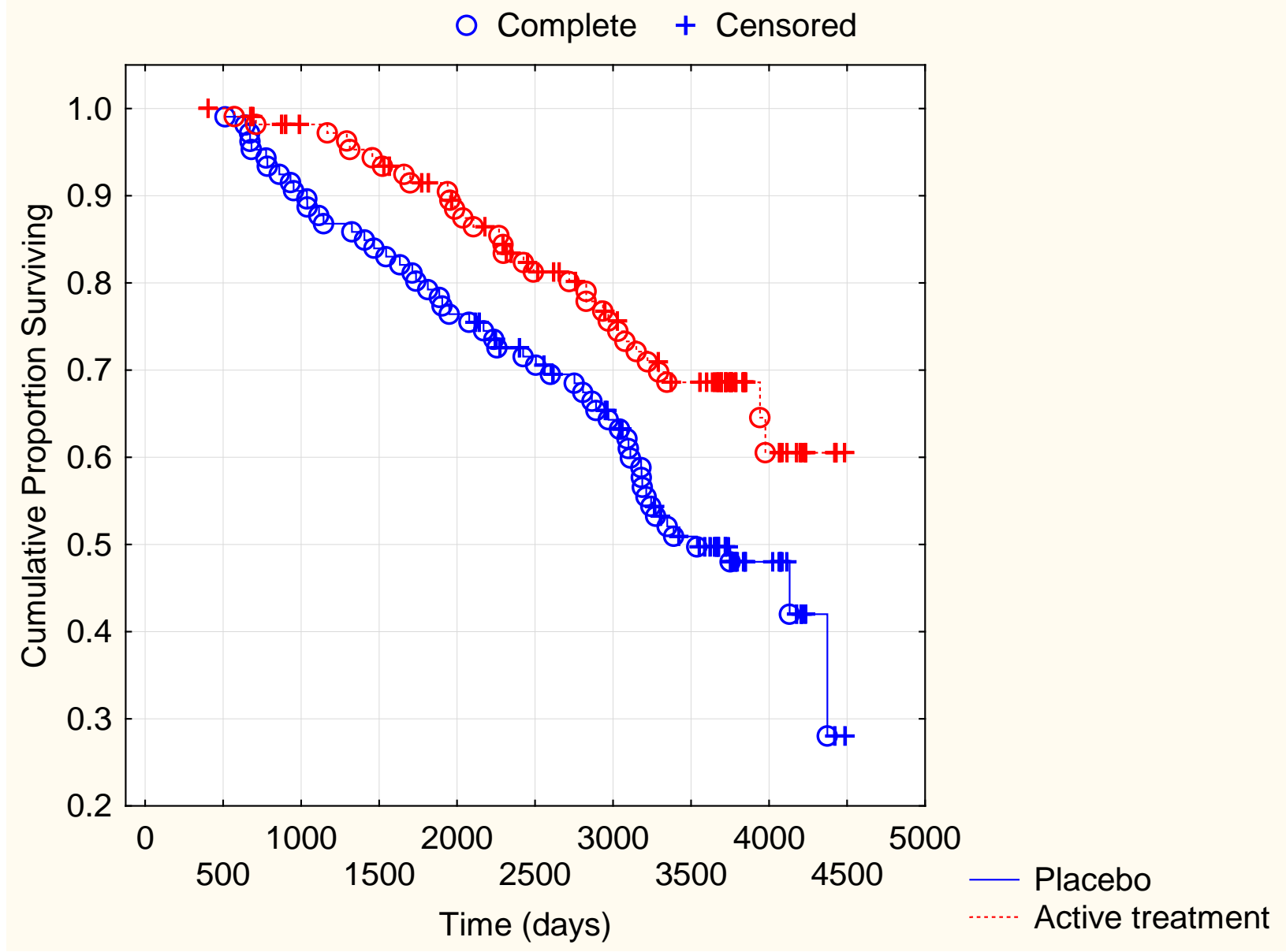

Patients at risk

\begin{tabular}{|l|c|c|c|c|c|c|}
\hline & $\begin{array}{c}\text { Study } \\
\text { start }\end{array}$ & $\mathbf{8 0 0}$ days & $\mathbf{1 6 0 0}$ days & $\mathbf{2 4 0 0}$ days & 3200 days & 4000 days \\
\hline $\begin{array}{l}\text { Active } \\
\text { treatment }\end{array}$ & 111 & 106 & 96 & 79 & 62 & 15 \\
\hline Placebo & 106 & 99 & 88 & 73 & 51 & 15 \\
\hline
\end{tabular}


Figure $3 b$

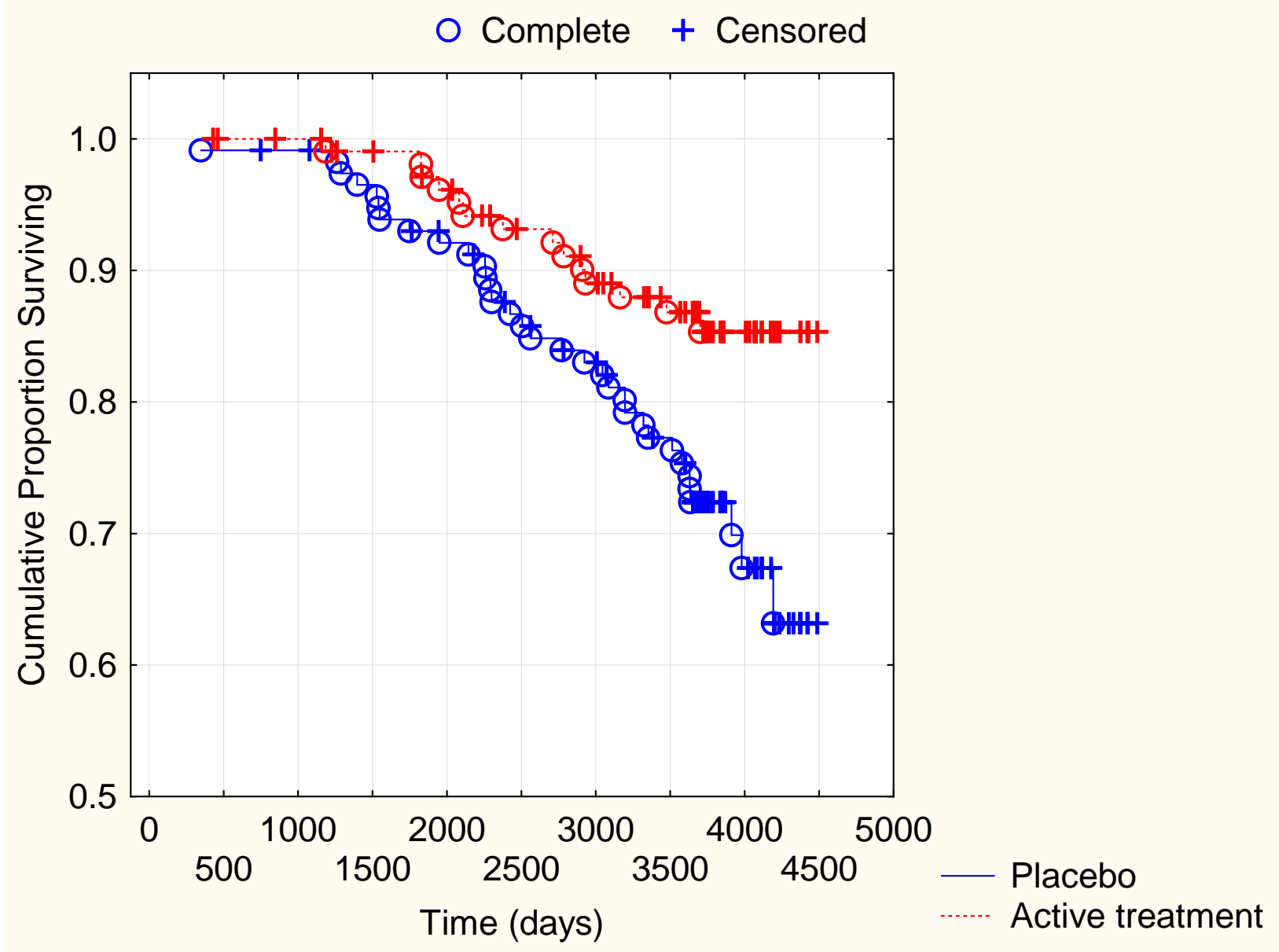

Patients at risk

\begin{tabular}{|l|c|c|c|c|c|c|}
\hline & $\begin{array}{c}\text { At study } \\
\text { start }\end{array}$ & $\mathbf{8 0 0}$ days & $\mathbf{1 6 0 0}$ days & $\mathbf{2 4 0 0}$ days & $\mathbf{3 2 0 0}$ days & $\mathbf{4 0 0 0}$ days \\
\hline $\begin{array}{l}\text { Active } \\
\text { treatment }\end{array}$ & 110 & 108 & 102 & 92 & 82 & 32 \\
\hline Placebo & 116 & 114 & 107 & 96 & 83 & 27 \\
\hline
\end{tabular}


Figure 4

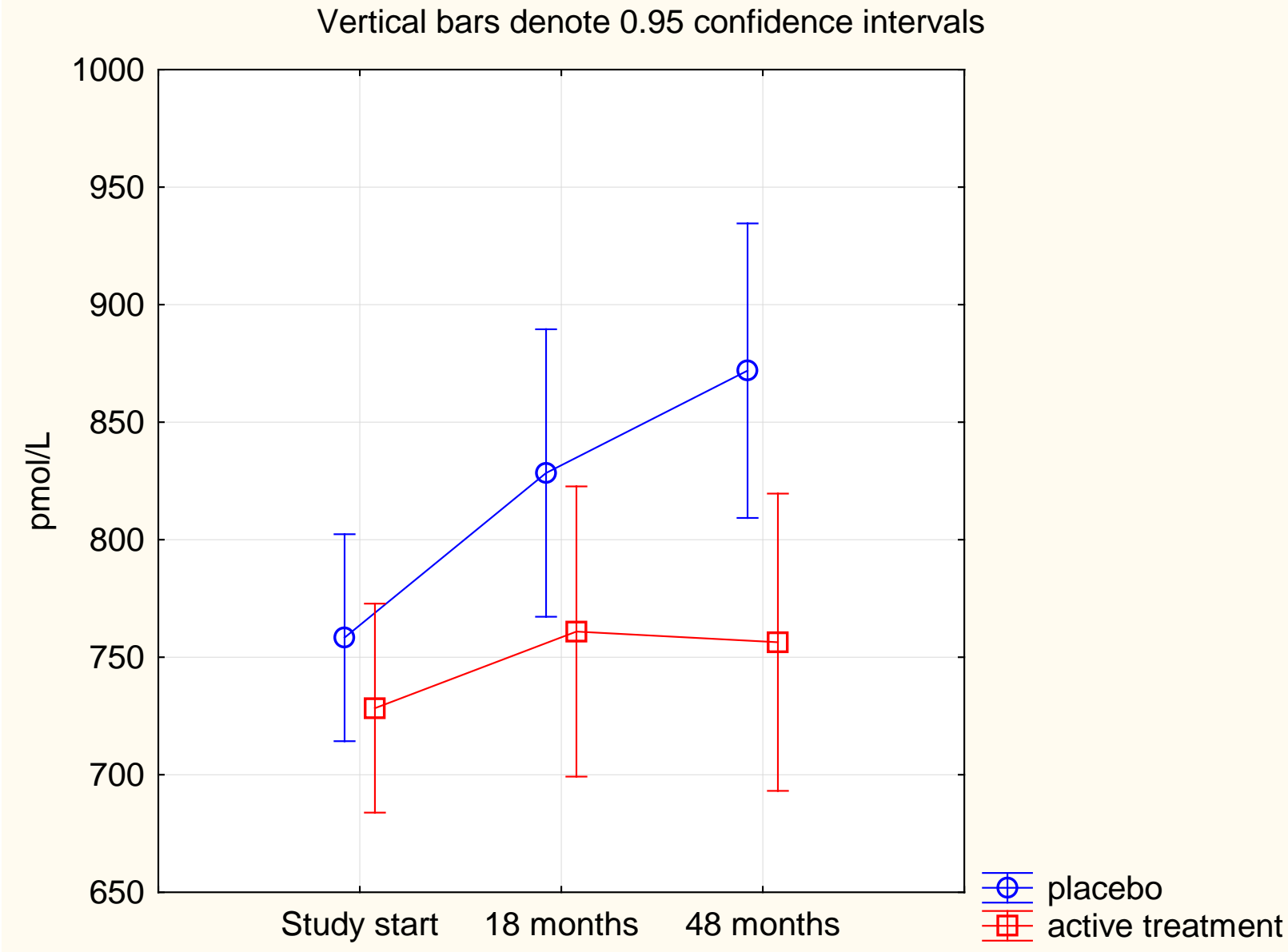


Figure $5 a$

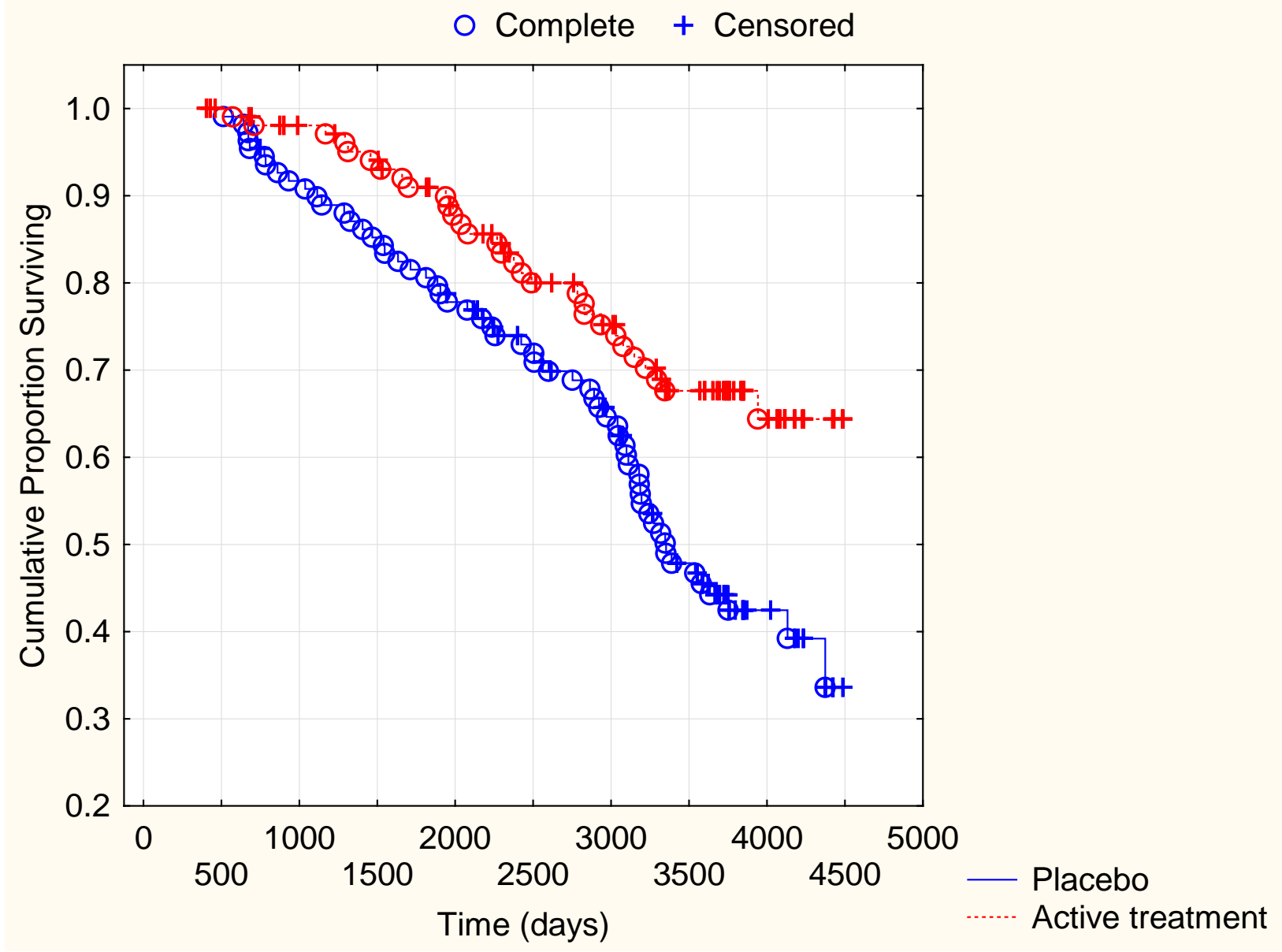

Patients at risk

\begin{tabular}{|l|c|c|c|c|c|c|}
\hline & $\begin{array}{c}\text { At study } \\
\text { start }\end{array}$ & $\mathbf{8 0 0}$ days & $\mathbf{1 6 0 0}$ days & $\mathbf{2 4 0 0}$ days & $\mathbf{3 2 0 0}$ days & $\mathbf{4 0 0 0}$ days \\
\hline $\begin{array}{l}\text { Active } \\
\text { treatment }\end{array}$ & 108 & 101 & 90 & 72 & 57 & 20 \\
\hline Placebo & 109 & 101 & 90 & 74 & 49 & 14 \\
\hline
\end{tabular}


Figure 5b

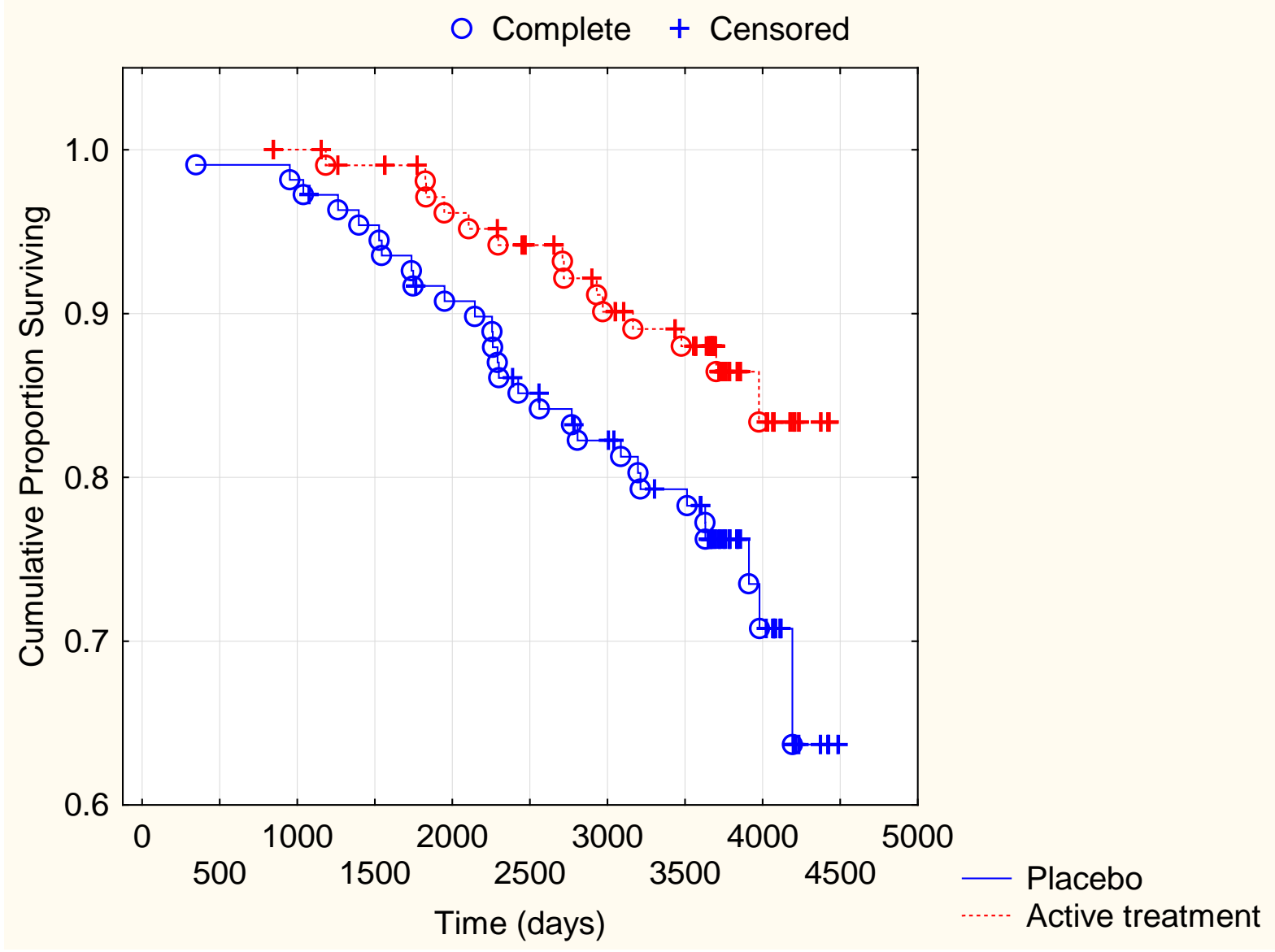

Patients at risk

\begin{tabular}{|l|c|c|c|c|c|c|}
\hline & $\begin{array}{c}\text { At study } \\
\text { start }\end{array}$ & $\mathbf{8 0 0}$ days & $\mathbf{1 6 0 0}$ days & $\mathbf{2 4 0 0}$ days & $\mathbf{3 2 0 0}$ days & $\mathbf{4 0 0 0}$ days \\
\hline $\begin{array}{l}\text { Active } \\
\text { treatment }\end{array}$ & 108 & 108 & 103 & 96 & 85 & 27 \\
\hline Placebo & 109 & 108 & 101 & 91 & 81 & 26 \\
\hline
\end{tabular}

